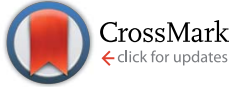

Cite this: RSC Adv., 2014, 4, 35099
Received 8th July 2014 Accepted 29th July 2014

DOI: $10.1039 / c 4 r a 06815 g$

www.rsc.org/advances

\section{Synthesis of high molecular weight polyglycolide in supercritical carbon dioxide $\uparrow$}

\begin{abstract}
Christian Schmidt, ${ }^{\text {ac }}$ Marc Behl, ${ }^{\text {b }}$ Andreas Lendlein ${ }^{\text {ab }}$ and Sabine Beuermann*ac
Polyglycolide (PGA) is a biodegradable polymer with multiple applications in the medical sector. Here the synthesis of high molecular weight polyglycolide by ring-opening polymerization of diglycolide is reported. For the first time stabilizer free supercritical carbon dioxide $\left(\mathrm{scCO}_{2}\right)$ was used as a reaction medium. $\mathrm{scCO}_{2}$ allowed for a reduction in reaction temperature compared to conventional processes. Together with the lowering of monomer concentration and consequently reduced heat generation compared to bulk reactions thermal decomposition of the product occurring already during polymerization is strongly reduced. The reaction temperatures and pressures were varied between 120 and $150{ }^{\circ} \mathrm{C}$ and 145 to 1400 bar. Tin(॥) ethyl hexanoate and 1-dodecanol were used as catalyst and initiator, respectively. The highest number average molecular weight of $31200 \mathrm{~g} \mathrm{~mol}^{-1}$ was obtained in 5 hours from polymerization at $120{ }^{\circ} \mathrm{C}$ and 530 bar. In all cases the products were obtained as a dry white powder. Remarkably, independent of molecular weight the melting temperatures were always at $(219 \pm 2)^{\circ} \mathrm{C}$.
\end{abstract}

\section{Introduction}

Polyglycolide (PGA) is of high interest for medical applications such as implants or drug release systems. ${ }^{\mathbf{1 - 4}}$ Compared to other dilactone based polyesters PGA degrades fast. Therefore a relatively high molecular weight is required to guarantee a sufficient residence time of the PGA for the therapy. However, the thermal decomposition of PGA starts already below the melting transition $\left(T_{\mathrm{m}}\right)$ of the PGA. When diglycolide is polymerized in the melt, the $T_{\mathrm{m}} \mathrm{s}$ of the oligo- and polyglycolide increase rapidly with increasing molecular weights. Accordingly the reaction temperature needs to be raised as well to avoid solidification of the reaction mixture. Here it needs to be considered that the polymerization of diglycolide is a strong exothermic reaction. An additional challenge to be met is the processing of the PGA into the intended application relevant bodies. The solubility of PGA in common solvents, which are suitable for biomaterials, is low and can only be achieved by processing at low temperatures at high pressures. Otherwise thermal degradations occurs, which becomes apparent by a brown coloring of the PGA.

${ }^{a}$ Institute of Chemistry, University of Potsdam, Karl-Liebknecht Str. 24-25, 14476 Potsdam, Germany

${ }^{b}$ Institute of Biomaterial Science, Helmholtz-Zentrum Geesthacht, Kantstraße 55, 14513 Teltow, Germany

'Institute of Technical Chemistry, Clausthal University of Technology, ArnoldSommerfeld-Str. 4, 38678 Clausthal-Zellerfeld, Germany

$\dagger$ Electronic supplementary information (ESI) available. See DOI: 10.1039/c4ra06815g
Supercritical carbon dioxide $\left(\mathrm{scCO}_{2}\right)$ possesses several favorable characteristics as reaction medium for polymer synthesis. It is a chemically inert, non-toxic, and environmentally benign gas, which can be easily separated from the product by reducing the pressure. ${ }^{5-7}$ Further, $\mathrm{CO}_{2}$ is well soluble in most polymers resulting in polymer swelling, which changes the mechanical and physical properties of the material. Therefore, $\mathrm{CO}_{2}$ can reduce the melting temperature $\left(T_{\mathrm{m}}\right)$ and the glass transition temperature $\left(T_{\mathrm{g}}\right)$ of polymers and monomers. The latter is caused by the plasticizing action of $\mathrm{CO}_{2} \cdot{ }^{5}$ For example, the $T_{\mathrm{g}}$ of poly(methyl methacrylate) (PMMA) is lowered by up to $60{ }^{\circ} \mathrm{C}$ at 100 bar in a $\mathrm{CO}_{2}$ atmosphere. ${ }^{5,8,9}$ Supercritical carbon dioxide was used as reaction medium for a wide variety of monomers encompassing conventional (meth)acrylates, fluoroolefins, and cyclic monomers leading to biodegradable polymers. ${ }^{10-22}$

It was hypothesized that $\mathrm{scCO}_{2}$ could be used as reaction medium to keep the PGA soluble during polymerization and by this avoid high reaction temperatures whereby high $M_{\mathrm{n}}$ can be achieved. In addition, $\mathrm{scCO}_{2}$ has proven to be an excellent process medium for particle formation. ${ }^{2324}$ Since particles of well-defined size are essential for the controlled drug delivery a combined process combing synthesis and shaping appears to be highly attractive.

Previously, ring-opening polymerizations (ROP) of cyclic monomers were carried out in $\mathrm{ScCO}_{2}$ as reaction medium using tin(II) ethyl hexanoate $\left(\mathrm{SnEH}_{2}\right)$ as catalyst. ${ }^{19,22}$ The polymerization mechanism for the cyclic diester diglycolide as monomer following a coordination-insertion mechanism. First, $\mathrm{SnEH}_{2}$ reacts with dodecanol to form the catalytic active tin(II) alkoxide. 
The alkoxide coordinates monomer and successive ringopening of the cyclic monomer occurs. Then, additional monomer units are coordinated and inserted between tin and the previously added monomer unit leading to chain growth. The polymerization is terminated by adding an excess amount of ethyl acetate, leaving an acetyl terminal group in the polymer.

The goal of this work was to explore whether high molecular weight PGA may be obtained using supercritical carbon dioxide as reaction medium and $\mathrm{SnEH}_{2}$ as catalyst. Since no information are available for ROP of diglycolide in non-stabilized systems under high-pressure conditions several monomer and catalyst concentrations as well as pressures and temperatures were explored.

\section{Experimental section}

\section{Materials}

Diglycolide (purity 99.9\%, Sigma, Munich, Germany) was recrystallized from a minimum amount of dry toluene. Tin(II) ethyl hexanoate (purity 95\%, Sigma), 1-dodecanol (purity 99.8\% Fluka), toluene (purity 99.9\%, Sigma), ethyl acetate (purity 99\%, VWR) were used as received. $\mathrm{CO}_{2}$ (purity 99.998\%) was obtained from Air Liquide (Düsseldorf, Germany).

\section{Typical polymerization procedure}

PGA synthesis under $\mathrm{scCO}_{2}$ conditions was performed in an optical high-pressure cell (RGT 601, material no. 2.4668, Arbed Saarstahl) with an inner volume of $6 \mathrm{~mL}$. A detailed description is given in ref. 25 . The cell was closed on one side and purged with argon before diglycolide (500 $\mathrm{mg}, 4.4 \times 10^{-3} \mathrm{~mol}$ ) as well as a solution of tin(II) ethyl hexanoate $\left(0.05 \mathrm{mg}, 1.2 \times 10^{-7} \mathrm{~mol}\right)$ and 1-dodecanol $\left(0.18 \mathrm{mg}, 9.7 \times 10^{-7} \mathrm{~mol}\right)$ in toluene $(0.1 \mathrm{~mL})$ were quickly transferred into the cell. Afterwards the cell was sealed, $\mathrm{CO}_{2}$ was added and the required pressure was adjusted using a manual high-pressure generator. To control temperature a resistive heating element (CGE Asthom) and a PIDcontroller (Eurotherm 815) were used. The reaction was quenched by releasing the pressure followed by quickly opening the cell to allow for fast removal of the product. The product is obtained as a white powder, as shown in Fig. 1. The crude product was isolated and subsequently purified by Soxhlet extraction with ethyl acetate for 4 hours, which resulted in a

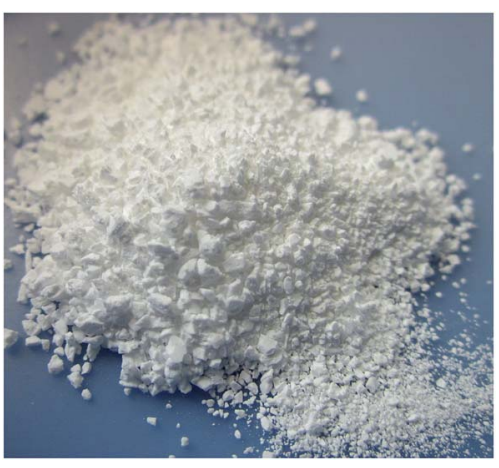

Fig. 1 PGA synthesized using $\mathrm{scCO}_{2}$ at $120^{\circ} \mathrm{C}$ (sample 30). white powder. Monomer conversions were determined gravimetrically.

\section{Characterization}

Differential scanning calorimetry (DSC). The thermal properties of the polymers were analyzed with a DSC 1/500658/200W STARe System from Mettler Toledo equipped with a FRS5sensor and nitrogen cooling. For each sample two heating and one cooling cycles were measured. Only the last heating cycle was analyzed to determine the thermal properties of the material. All samples were analyzed using a constant heating and cooling rate of $10 \mathrm{~K} \mathrm{~min}^{-1}$ in a temperature range from $-60{ }^{\circ} \mathrm{C}$ to $280{ }^{\circ} \mathrm{C}$.

Elemental analysis (EA). Elemental analyses were performed with a Vario EL III (Elementar) instrument with an error limit of $\pm 0.3 \%$ for carbon and hydrogen and $\pm 0.5 \%$ for oxygen was used.

Fourier transform-infrared spectroscopy (FT-IR). FT-IR spectra were recorded with a resolution of $2 \mathrm{~cm}^{-1}$ and 32 scans using a Bruker Vertex 70 spectrometer with a globar source, a $\mathrm{KBr}$ beam splitter and a DTGS detector. All samples were measured as $\mathrm{KBr}$ tablets.

MALDI-TOF mass spectroscopy (MALDI-TOF). MALDI-TOF spectra were attained using an Ultraflextreme mass spectrometer (Bruker) in the positive linear and/or reflection mode and trans-2(3-(4-tert-butylphenyl)-2-methyl-2-propenylidene)-malonitrile (DCTB in KTFA/THF) as a matrix. Ions were generated by a nitrogen laser emitting at $337 \mathrm{~nm}$ and were accelerated at 20 $\mathrm{kV}$. The detector voltage was $2.4 \mathrm{kV}$, and the mass spectra were averaged from 500 to 6500 laser shots.

Size-exclusion chromatography (SEC). Molecular weight distributions were measured with an SEC setup consisting of an Agilent 1200 HPLC pump with a refractive index (Agilent) detector with a flow rate of $1 \mathrm{~mL} \mathrm{~min}^{-1}$ and hexafluoroisopropanol (HFIP, Fluorochem, 99\%) containing potassium trifluoroacetate (0.05 M) (Fluka, 99\%) as eluent. Poly(methyl methacrylate) (PSS) standards were used for calibration. All analyses were performed at $35{ }^{\circ} \mathrm{C}$ with three columns (PSS-PFG $1000 \AA$ A, $7 \mu \mathrm{m}$ particle size, $8.0 \times 300 \mathrm{~mm}$; PSS-PFG $300 \AA$, $7 \mu \mathrm{m}$ particle size, $8.0 \times 300 \mathrm{~mm}$ and PSS-PFG $100 \AA$, $7 \mu \mathrm{m}$ particle size, $8.0 \times 300 \mathrm{~mm}$ ). Due to poor solubility of the samples with the highest molecular weights and crystallinity (marked with an asterisk in Table 1) $M_{\mathrm{n}}$ and PDI of these samples reported represent only the soluble fraction of the material.

Thermal gravimetric analysis (TGA). The thermal degradation of the polymers was measured with a Netzsch TGA 204 Phoenix (Selb, Germany) instrument at a constant heating rate of $10 \mathrm{~K} \mathrm{~min}^{-1}$ in a temperature range from $25{ }^{\circ} \mathrm{C}$ to $400{ }^{\circ} \mathrm{C}$ under argon atmosphere.

Wide-angle X-ray scattering (WAXS). The degree of crystallinity of the PGA samples was measured with a X-ray diffractometer Bruker D8 Discover. The X-ray generator was operated at $40 \mathrm{kV}$ and $40 \mathrm{~mA}$. A two-dimensional detector operating in a $1024 \times 1024$ pixel mode was used. The distance between sample and detector was chosen to be $150 \mathrm{~nm}$ and the selected 
Table 1 Experimental conditions and results (temperature $T$, pressure $p$, reaction time $t$, monomer concentration $c_{M}$, catalyst concentration $c_{\text {cat, }}$ initiator concentration $c_{1}$, conversion $x$ determined by gravimetry, number average molecular weight $M_{n}$ and polydispersity PDI obtained from SEC calibrated with PMMA) (* indicates samples, which were not completely soluble in HFIP; SEC of soluble sample fraction)

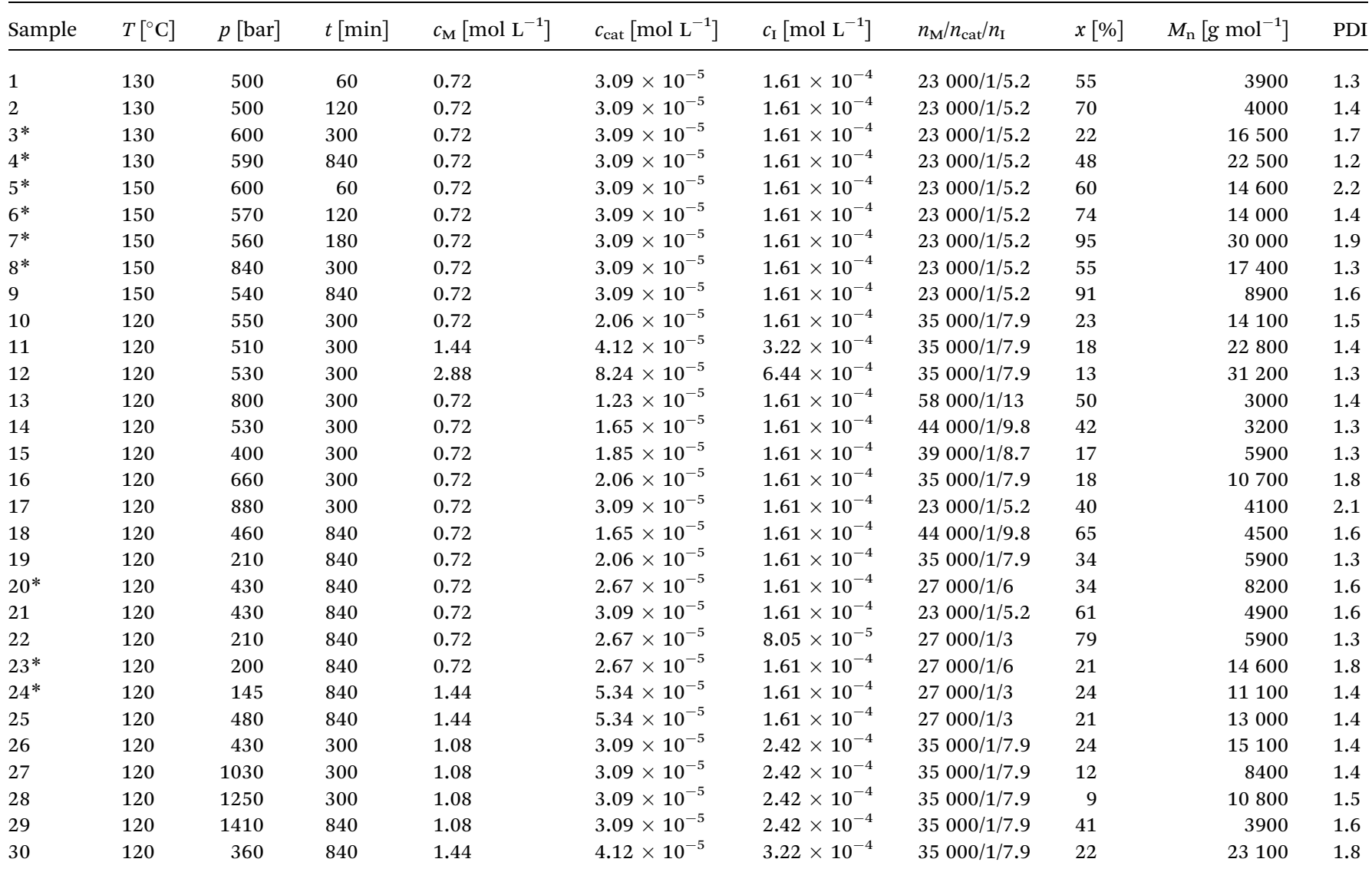

wavelength was $0.154 \mathrm{~nm}$. By arranging the detector in an angle of $2 \theta=30^{\circ}$ a scattering angle between $2 \theta=12.5^{\circ}$ and $47.5^{\circ}$ was detected. The isotropic grid was converted into a one-dimensional scattering curve by integration over an angle $\chi=120^{\circ}$ over the $2 \theta$ area. Such an operation was possible as the raw patterns were all isotropic. Accordingly, the 1-dimensional curve contains the same information as the 2-dimensional pattern. This curve was divided into peaks that belong to the amorphous or crystalline phase by using the Bruker analytical software TOPAS ${ }^{\circledR}$. The degree of crystallinity was calculated from the ratio of the integrals of both phases by fitting them using a Pearson VII function.

\section{Results and discussion}

The polymerization conditions and the experimental results are summarized in Table 1 . The polymerization kinetics were explored by quenching the reactions after different reaction times $t$ and determining the number average molecular weight $M_{\mathrm{n}}$, whereby the other reaction conditions were kept identical. As shown in Fig. 2 an increase in $t$ at $130{ }^{\circ} \mathrm{C}$ resulted in an increase in $M_{\mathrm{n}}$ to $22500 \mathrm{~g} \mathrm{~mol}^{-1}$ after $14 \mathrm{~h}$ (samples 1 to 4 ). When $T$ was raised to $150{ }^{\circ} \mathrm{C}$ a PGA with $M_{\mathrm{n}}$ of $30000 \mathrm{~g} \mathrm{~mol}^{-1}$ was obtained after $3 \mathrm{~h}$ (sample 7 ). It should be noted that only a

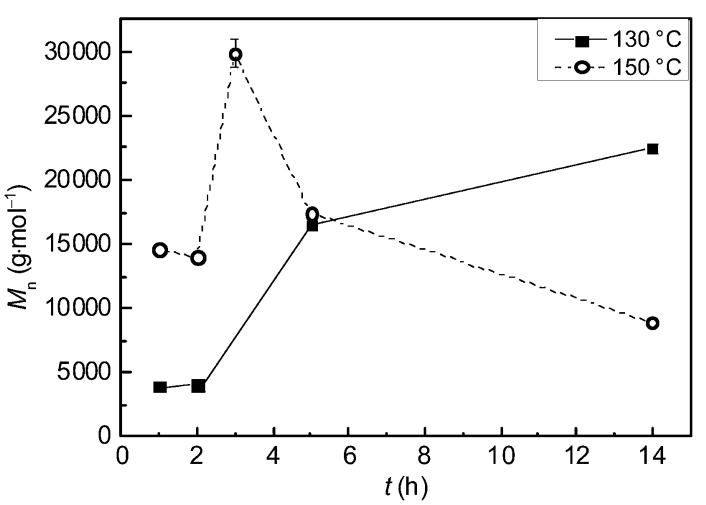

Fig. 2 Influence of reaction time $t$ on the number average molecular weight $M_{n}$ of PGA polymerized in the presence of $\mathrm{scCO}_{2}$ at $130{ }^{\circ} \mathrm{C}$ and $\bigcirc 150^{\circ} \mathrm{C}$. The lines indicate guides for the eye, margin of error are in most cases smaller than symbol size.

fraction of the polymer material was soluble in HFIP and analyzed via SEC. Thus, the true $M_{\mathrm{n}}$ value is expected to be even higher. A further increase in $t$ resulted in a material that is completely soluble in HFIP and exhibits a decrease in $M_{\mathrm{n}}$ (Fig. 2, samples 5 to 9 in Table 1), which might be attributed to thermal decomposition. It is remarkable to note that even at $150{ }^{\circ} \mathrm{C}$ the 
PGA was obtained as a white powder. At first sight the finding of white polymer might be in conflict with the decrease in $M_{\mathrm{n}}$ at higher reaction times. However, low molecular weight decomposition products could be extracted by $\mathrm{scCO}_{2}$ during the depressurization process. The data indicate that an increase in $T$ results in an enhancement of molecular weight and conversion. Because of the complex interplay between polymerization conditions and thermal decomposition of the polymer, the reaction conditions were varied with respect to $c_{\mathrm{M}}, c_{\text {cat }}, p$, and $T$.

Consideration of the monomer concentration shows that when $c_{\mathrm{M}}$ was raised from 0.72 (sample 10) to $2.88 \mathrm{~mol} \mathrm{~L}^{-1}$ (sample 12) $M_{\mathrm{n}}$ increased from 14100 to $31200 \mathrm{~g} \mathrm{~mol}^{-1}$ at $120{ }^{\circ} \mathrm{C}$. The corresponding molecular weight distributions are shown in Fig. 3 A. Sample 12 obtained with $c_{\mathrm{M}}=2.88 \mathrm{~mol} \mathrm{~L}^{-1}$ shows the highest $M_{\mathrm{n}}$ that was obtained within this study. Further, the molecular weight distributions do not show significant amounts of low molecular weight material. At first sight, this finding is surprising, since frequently ring-opening polymerizations yield cyclic oligomers as by-products. On the other hand, a recent kinetic study on ROP of glycidol revealed that side reactions being important at ambient pressure polymerizations are completely eliminated at elevated pressure. ${ }^{26}$ ${ }^{1} \mathrm{H}-\mathrm{NMR}$ spectra of PGA were recorded in a mixture of HFIP and $\mathrm{CDCl}_{3}$. In addition to the solvent-derived peaks, only a single
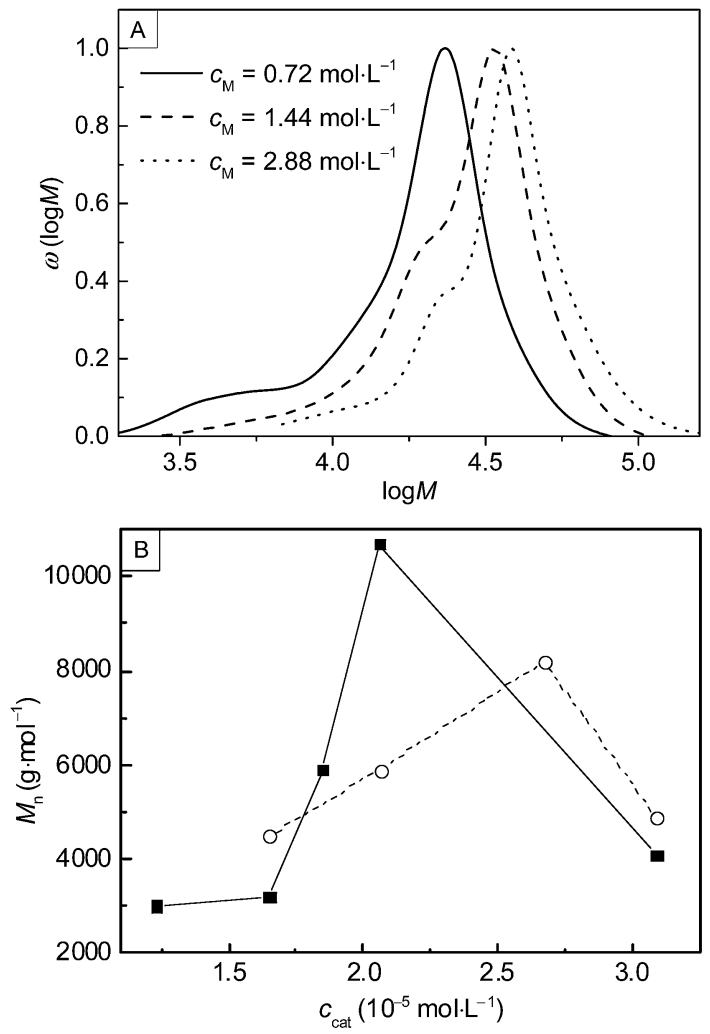

Fig. 3 (A) Molecular weight distributions of PGA obtained from reactions with varying $C_{M}$ at $120^{\circ} \mathrm{C}, 500$ bar, and 5 hours with $n_{M} / n_{\text {cat }} /$ $n_{\mathrm{I}}=35000 / 1 / 7.9$ : (I) $0.72 \mathrm{~mol} \mathrm{~L}^{-1}$ (II) $1.44 \mathrm{~mol} \mathrm{~L}^{-1}$ (III) $2.88 \mathrm{~mol} \mathrm{~L}^{-1}$. (B) Number average molecular weights $M_{n}$ as a function of $c_{c a t}$ at $(O)$ $120^{\circ} \mathrm{C}, 660$ bar, 5 hours, $C_{M}=0.72 \mathrm{~mol} \mathrm{~L}^{-1}$ and $(\boldsymbol{\square})$ at $120^{\circ} \mathrm{C}, 400$ bar, 14 hours, $C_{M}=0.72 \mathrm{~mol} \mathrm{~L}^{-1}$. peak at $4.87 \mathrm{ppm}$ is observed, which is assigned to $\mathrm{CH}_{2}$ in the polymer. This finding also suggests that significant amounts of oligomeric side products were not obtained. A typical ${ }^{1} \mathrm{H}-\mathrm{NMR}$ spectrum and a description of the sample preparation are contained in the ESI. $\dagger$

In addition, the influence of the concentrations of catalyst, $c_{\text {cat }}$, on the molecular weight has been investigated. The results obtained for the variation of $c_{\text {cat }}$ are presented in Fig. 3B (samples 13 to 17 and 18 to 21). The experiments suggest that $c_{\text {cat }}$ has an optimum value to yield high molecular weight PGA. However, conversion seems to be minimal for these values. A similar behaviour is found for the variation of the dodecanol concentration, $c_{\mathrm{I}}: M_{\mathrm{n}}$ increases from 5900 to $14600 \mathrm{~g} \mathrm{~mol}^{-1}$ upon raising $c_{\mathrm{I}}$ from $8.05 \times 10^{-5}$ to $1.61 \times 10^{-4} \mathrm{~mol} \mathrm{~L}^{-1}$ (samples 22 and 23), while conversions decrease from 79 to $21 \%$. It is highly likely that these observations may be attributed to the influence of water. Dodecanol acts as a protic co-initiator to increase the nucleophilicity of the catalyst and enables the ring-opening reaction. ${ }^{2,27}$ Water fulfils the same task as dodecanol, but leads to shorter chain lengths. Therefore, it is required to either use completely dried materials or to increase $c_{\mathrm{I}}$ to suppress the activation of the catalyst by water molecules. As sample 23 shows, by enhancing $c_{\mathrm{I}}$ the activation of catalyst molecules by the initiator is promoted yielding polymer with higher $M_{\mathrm{n}}$.

The influence of $c_{\text {cat }}$ can be explained by a delicate interplay as an increasing number of catalyst molecules at constant $c_{\mathrm{I}}$ favour the activation by water molecules. However, the data suggests that the effect occurs also at low $c_{\text {cat }}$. For low $c_{\text {cat }}$ low $M_{\mathrm{n}}$ at increased conversion were determined. It is most likely, that the increased relative concentration of aqueous impurities compared to active species causes an enhancement of the catalyst activation by water.

The data in Table 1 suggests that the molecular weight is also influenced by pressure $(p)$. When $p$ was increased from 145 (sample 24) to 480 bar (sample 25) $M_{\mathrm{n}}$ increased from 11100 to $13000 \mathrm{~g} \mathrm{~mol}^{-1}$. Such a behaviour was expected as at low pressures significant changes of the $\mathrm{CO}_{2}$ properties occur when $p$ is increased. Once a certain pressure level is reached the physico-

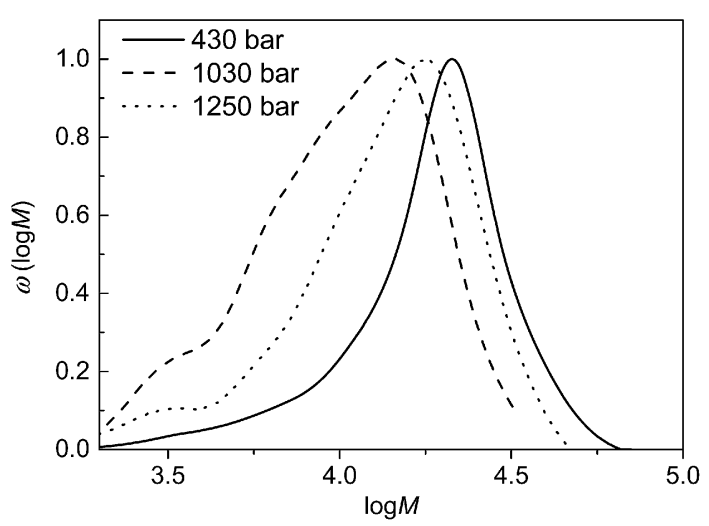

Fig. 4 Molecular weight distributions obtained at the indicated pressures and the following reaction conditions: 5 hours, $120{ }^{\circ} \mathrm{C}, C_{M}=$ $1.08 \mathrm{~mol} \mathrm{~L}^{-1}, n_{\mathrm{M}} / n_{\text {cat }} / n_{1}=35000 / 1 / 7.9$. 
chemical properties change only slightly, ${ }^{5}$ and only a small influence is expected to occur. On the contrary, the molecular weight distributions shown in Fig. 4 indicate that an increase in pressure from 430 to 1250 bar (sample 26 to 28 ) leads to a distinct decrease in the peak molecular weight of the distribution while dispersities are rather similar. Moreover, with increasing pressure monomer conversions are significantly lowered.

The pressure influence on the molecular weight distribution may be explained as follows. Firstly, the polymerization mechanism is considered. The ring-opening of the cyclic diester results in an increase in the molar volume, and thereby, this step is hindered at high pressure. This reasoning is in agreement with the finding that a reaction leading to a cyclic or a linear product might be directed towards the cyclic product at low pressure, whereas the linear product is obtained at high pressure. ${ }^{28}$ Moreover, interactions of the catalyst with $\mathrm{CO}_{2}$ need to be considered. Previously, it was shown that ROP in $\mathrm{scCO}_{2}$ with Sn catalysts proceeds slower at higher pressure. It was discussed that $\mathrm{CO}_{2}$ competes with the coordination of the monomer at the catalyst site, thus, reducing the coordination of the monomer. ${ }^{17,18}$ The coordination of the catalyst with $\mathrm{CO}_{2}$ was suggested to be reversible since no carbonate species were obtained after the polymerization. In addition, it was reported that the effect is less pronounced at higher temperature. While the literature mostly refers to polymerizations at $40{ }^{\circ} \mathrm{C}$ in this work the lowest temperature is $120^{\circ} \mathrm{C}$. Thus, it is anticipated that the coordination with $\mathrm{CO}_{2}$ is much less important. This reasoning is supported by the following finding: ${ }^{19}$ it was shown that at otherwise identical conditions ROP of $\varepsilon$-caprolactone at $80{ }^{\circ} \mathrm{C}$ in toluene proceeds only by a factor of 1.3 faster than in $\mathrm{scCO}_{2}$. The moderate decrease in the presence of $\mathrm{scCO}_{2}$ was explained with a fast equilibrium and the rather short time interval in which the chain ends are in the dormant carbonated state.

On the other hand the linear monomer units in the polymer chains might be more closely packed, which should lead to a higher polymerization rate at higher pressure. In addition, reaction rates are often increased at higher pressure due to higher monomer densities. ${ }^{5,29}$ Another important aspect is the phase behaviour of the monomer-polymer- $\mathrm{CO}_{2}$ system. Generally, with increasing pressure the solubility of polymer and monomer in $\mathrm{CO}_{2}$ is improved. ${ }^{5,29,30}$ Because of the opposing influences of pressure on the polymerization the reaction pressure should be at an intermediate level to yield high molecular weight polymer.

These observations show that there is a complex interplay between the relevant reaction parameters. Therefore, in future it is crucial to determine the optimum reaction conditions to yield high molecular weight polymer. In this study PGA with the highest number average molecular weight of $31200 \mathrm{~g} \mathrm{~mol}^{-1}$ was obtained after $5 \mathrm{~h}$ at $120^{\circ} \mathrm{C}$ with $c_{\mathrm{M}}=2.88 \mathrm{~mol} \mathrm{~L}^{-1}$ and $n_{\mathrm{M}} /$ $n_{\text {cat }} / n_{\mathrm{I}}$ of 35000 to 1 to 7.9 at 530 bar (sample 12). Since the reaction conditions were not yet optimized with respect to the presence of water, it is anticipated that even higher molecular weight material may become available.
To the best of our knowledge previously only Bratton, Brown and Howdle reported on the synthesis of PGA with $\mathrm{scCO}_{2}$ as reaction medium. ${ }^{22}$ The reactions were carried out for 24 hours in dispersion using a hydrocarbon stabilizer at $80{ }^{\circ} \mathrm{C}$ and pressures around 250 bar. As catalyst system $\mathrm{SnEH}_{2}$ and butanol were used. In all cases $M_{\mathrm{n}}$ values ranging from 4200 to $4900 \mathrm{~g} \mathrm{~mol}^{-1}$ were derived. These values are significantly lower than obtained in our work. The reasons may be seen in the lower temperature and the dispersed nature of the system in ref. 22. During the suspension polymerization the $\mathrm{CO}_{2}$-induced lowering of $T_{\mathrm{m}}$ should not play an important role.

The molecular weights of the PGA samples were determined by SEC analyses. In addition, MALDI-TOF was used to characterize some of the polymer samples. The MALDI-TOF mass spectrum of a sample with an SEC-derived $M_{\mathrm{n}}$ of $3900 \mathrm{~g} \mathrm{~mol}^{-1}$ (full distribution given in Fig. 5A) shows a molecule ion peak at $m / z=5420 \mathrm{~g} \mathrm{~mol}^{-1}$ (Fig. 5B) (sample 29), which correlates with 89 monomer units, the end groups 1-dodecanol and acetyl originating from the catalyst and termination with ethyl acetate, respectively, and a $\mathrm{Na}^{+}$ion. In the MALDI-TOF spectrum the signals show a characteristic difference $m / z=116 \mathrm{~g} \mathrm{~mol}^{-1}$, which can be attributed to a diglycolide unit. Signals separated by $m / z=58 \mathrm{~g} \mathrm{~mol}^{-1}$, reflecting the mass of a glycolide unit, were not found. The molecular weight distribution and the MALDITOF mass spectra in Fig. 5 show some deviations in shape and the molecular weights are different. Jackson et al. showed that MALDI-TOF mass spectra are not representative for the molecular weight distribution in cases where the dispersities are higher than 1.2. ${ }^{31}$ That effect is due to instrumental limitations of MALDI-TOF and the use of different scaling of the data by both methods. The differences in $M_{\mathrm{p}}$ (most probable peak) values determined by SEC and MALDI-TOF are strongly increased for higher PDI. ${ }^{31,32}$ As the measured sample shows a SEC-derived PDI of 1.6 such a behaviour may be expected. In addition, differences in molecular weight may be caused by the PMMA calibration of the SEC set-up.

FT-IR spectra allowed for an easy identification of the polymer. The spectra given in Fig. 6 clearly show that most bands are present in both polymer and monomer spectra. However, in the wavenumber range from 1600 to $500 \mathrm{~cm}^{-1}$ the monomer
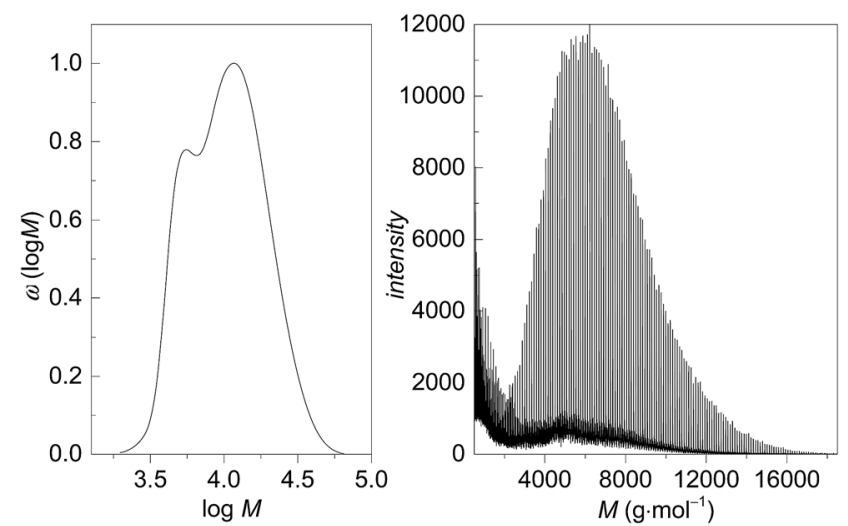

Fig. 5 Comparison of (A) SEC-derived molecular weight distribution and (B) MALDI-TOF mass spectrum. 


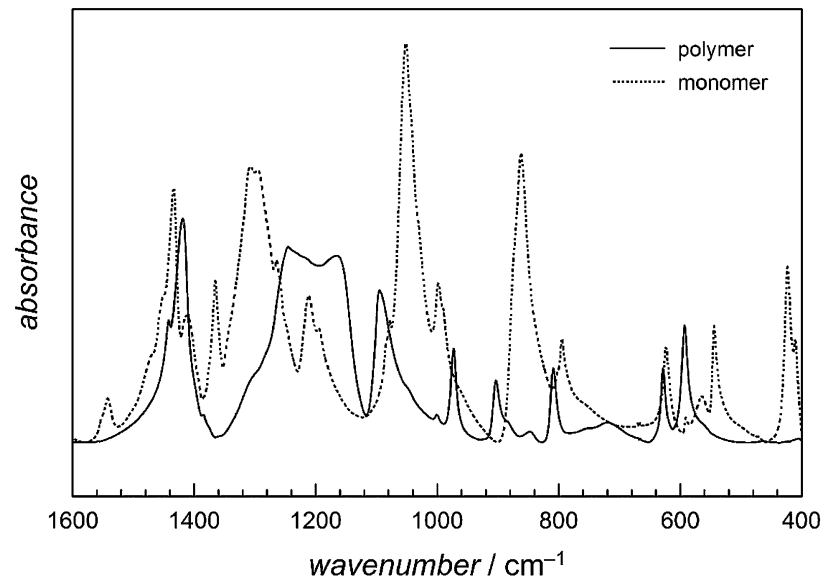

Fig. 6 IR spectra of diglycolide and of sample $29\left(M_{n}\right.$ of $\left.3900 \mathrm{~g} \mathrm{~mol}^{-1}\right)$.

related absorption bands show a strongly different shape compared to the polymer spectra. Particularly important is the area around $1250 \mathrm{~cm}^{-1}$, which is assigned to the OCO stretching vibration. The change of the absorption behaviour is most likely a result of the transformation of the cyclic monomer to a linear polymer. These absorption bands are highly specific for the polymer and independent of its $M_{\mathrm{n}}$ indicating the synthesis of polyglycolide in all cases. Elemental analyses confirm these conclusions. The data shows just slight variations in the polymer's elemental contents. The carbon content varies between 40.5 and $41.4 \%\left(\mathrm{C}_{\text {calculated }}=41.4 \%\right)$, the hydrogen content between 2.5 and $2.7 \%\left(\mathrm{H}_{\text {calculated }}=3.4 \%\right)$ and the oxygen content between 52.9 and $53.5 \%\left(\mathrm{O}_{\text {calculated }}=55.2 \%\right)$.

The thermal properties of the PGA samples were investigated using DSC. The glass transition temperature $T_{\mathrm{g}}$ ranged from 31 to $40{ }^{\circ} \mathrm{C}$ and occurred to be independent of $M_{\mathrm{n}}$. The melting temperature $T_{\mathrm{m}}$ shows a slight variation by $4{ }^{\circ} \mathrm{C}$ ranging from 217 to $221{ }^{\circ} \mathrm{C}$. These values are in excellent agreement with values between 220 and $228^{\circ} \mathrm{C}$ reported in ref. 33 and 34 . As an example, Fig. 7A presents the DSC curve of the PGA sample of $M_{\mathrm{n}}=3900 \mathrm{~g} \mathrm{~mol}^{-1}$ showing a $T_{\mathrm{m}}$ of $(219 \pm 2)^{\circ} \mathrm{C}$, while both the polymer samples with higher $M_{\mathrm{n}}$ of 13000 and $23100 \mathrm{~g} \mathrm{~mol}^{-1}$ possess a $T_{\mathrm{m}}$ of $(220 \pm 2)^{\circ} \mathrm{C}$. In all cases the data clearly shows that the thermal properties are almost independent of $M_{\mathrm{n}}$. Since an increase in $T_{\mathrm{m}}$ with increasing molecular weight is expected for polyesters these results indicate that the critical $M_{\mathrm{n}}$ at which the $T_{\mathrm{m}}$ is a function of $M_{\mathrm{n}}$ should be below $3900 \mathrm{~g} \mathrm{~mol}^{-1}$.

The insensitivity of $T_{\mathrm{m}}$ towards $M_{\mathrm{n}}$ can be explained by the high crystallinity detected by WAXS measurements. All samples presented in Fig. 8 show a significant amorphous peak at $2 \theta=$ $20^{\circ}$ and peaks assigned to the two crystalline phases at $2 \theta=23^{\circ}$ and $2 \theta=29^{\circ}$. Even at low $M_{\mathrm{n}}$ and thereby smaller segments high degrees of crystallinity (DOC) occur. The sample with $M_{\mathrm{n}}=3900$ $\mathrm{g} \mathrm{mol}^{-1}$ has a DOC of $(45.4 \pm 0.4) \%$ that is just slightly smaller than for the $13000 \mathrm{~g} \mathrm{~mol}^{-1}$ sample with DOC of $(48.2 \pm 0.4) \%$ and the $23100 \mathrm{~g} \mathrm{~mol}^{-1}$ sample with $(46.3 \pm 0.7) \%$. These values are within the range from 40 to $55 \%$ reported in literature. ${ }^{35,36}$

Furthermore, thermal gravimetric analysis (TGA) was used to study the decomposition behaviour of the materials. Fig. 7B
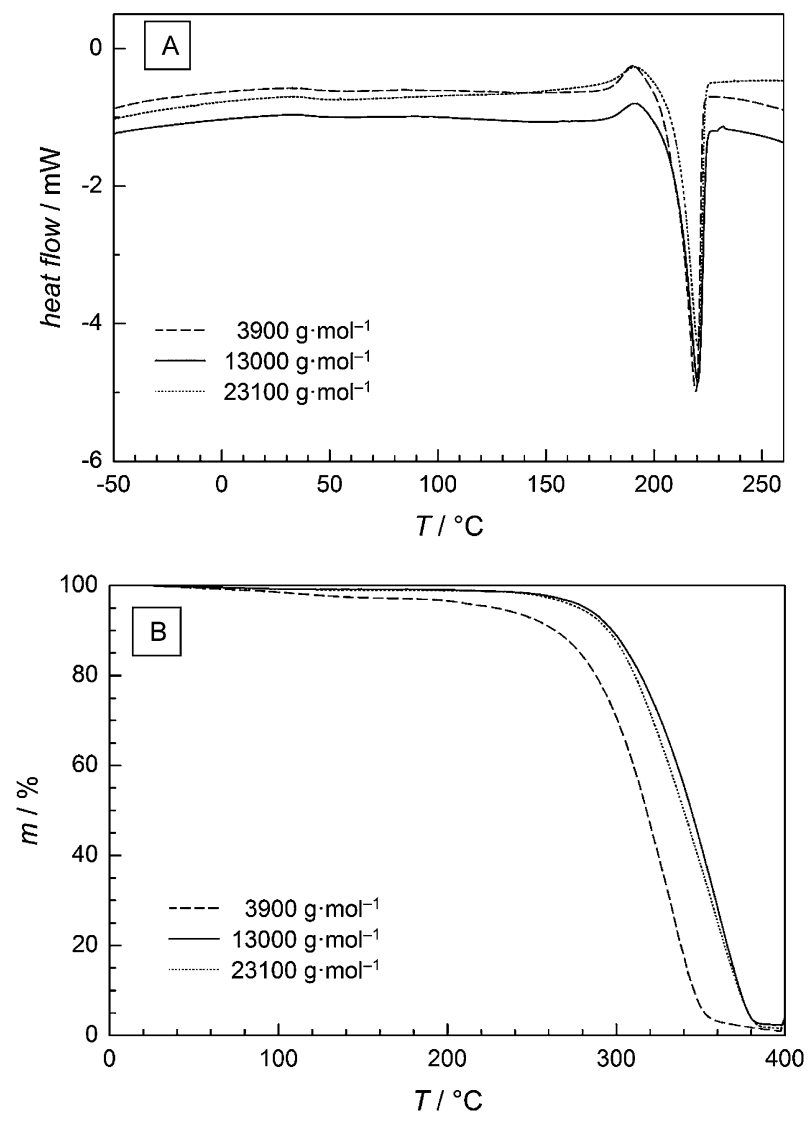

Fig. 7 Thermal analyses of PGA samples with different $M_{n}$ values as indicated: (A) DSC (B) TGA.

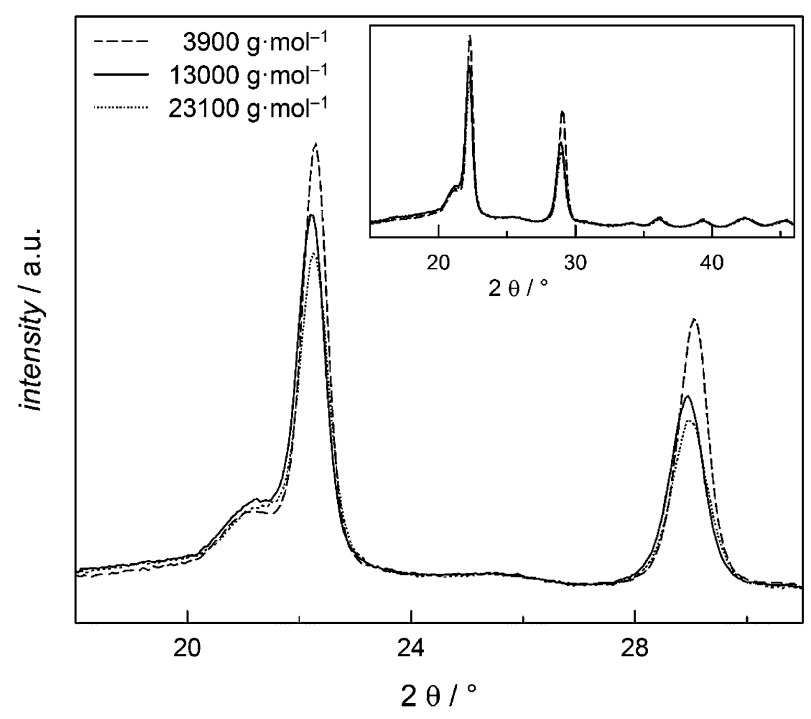

Fig. 8 WAXS results for PGA with varying $M_{n}$ values as indicated.

shows that a first decomposition occurs at lower $T$ in case of the low $M_{\mathrm{n}}$ sample. Decomposition occurs most likely by scission of the end groups. The inflection points of the decomposition curve are detected at $310^{\circ} \mathrm{C}$ for the low $M_{\mathrm{n}}$ sample and at $340^{\circ} \mathrm{C}$ for higher $M_{\mathrm{n}}$ samples. Beyond $360{ }^{\circ} \mathrm{C}$ for the low $M_{\mathrm{n}}$ sample 
and beyond $380^{\circ} \mathrm{C}$ for higher $M_{\mathrm{n}}$ samples no further significant weight loss is found. As the decomposition occurs in just one step no intermediate products are generated. Therefore, the data suggests that the decomposition is increased until a certain $M_{\mathrm{n}}$ value is reached. Beyond this $M_{\mathrm{n}}$ no further change in thermal decomposition is found.

With respect to applications the mechanical behaviour of the material is of interest. However, so far the mechanical behaviour could not be investigated. The high-pressure reaction cells yield only small quantities of product, which were not sufficient for the preparation of standardized samples via extrusion and injection moulding. In addition, testing of PGA films was not feasible, because no films suitable for characterization of mechanical properties could be obtained.

\section{Conclusions}

High molecular weight PGA was synthesized using $\mathrm{scCO}_{2}$ as reaction medium. Within this study the highest $M_{\mathrm{n}}$ of $31200 \mathrm{~g}$ $\mathrm{mol}^{-1}$ was obtained at the following reaction conditions: $120^{\circ} \mathrm{C}$ and 530 bar with $8.24 \times 10^{-5} \mathrm{~mol} \mathrm{~L}^{-1}$ catalyst, $6.44 \times 10^{-4} \mathrm{~mol}$ $\mathrm{L}^{-1}$ initiator, and $2.88 \mathrm{~mol} \mathrm{~L}^{-1}$ monomer at a reaction time of 5 hours (sample 12). The data suggests that the molecular weight of the polyester is enhanced by increasing $c_{\mathrm{M}}$. At already comparatively low temperatures and, thus, avoiding thermal decomposition, high molecular weight polymers are accessible. Furthermore, no solvents or any additives, e.g. as surfactants, were involved for the synthesis, which makes this process interesting for degradable polymers intended for biomedical usage.

The use of $\mathrm{scCO}_{2}$ as reaction medium is not only interesting with respect to obtaining a product free of any residues from solvent or additives, it is also attractive for post-polymerization processes. Being able to synthesize PGA in $\mathrm{scCO}_{2}$ constitutes a prerequisite for developing integrated processes combining polymer synthesis, formulation, and shaping of the material.

\section{References}

1 S. Kaihara, S. Matsumura, P. Fisher and A. Mikos, Nat. Protoc., 2006, 2, 2767-2771.

2 O. Dechy-Cabaret, B. Martin-Vaca and D. Bourissou, Chem. Rev., 2004, 104, 6147-6176.

3 J. A. Hyatt, J. Org. Chem., 1984, 49, 5097-5101.

4 D. K. Gilding and A. M. Gilding, Polymer, 1979, 20, 14591464.

5 T. Meyer and M. F. Kemmere, Supercritical Carbon Dioxide in Polymer Reaction Engineering, Wiley-VCH, Weinheim, 2005.

6 A. I. Cooper, J. Mater. Chem., 2000, 10, 207-234.

7 A. I. Cooper, Adv. Mater., 2003, 15, 1049-1059.

8 R. Pini, G. Storti, M. Mazzotti, H. Tai, K. M. Shakesheff and S. M. Howdle, Macromol. Symp., 2007, 259, 197-202.

9 R. Pini, G. Storti, M. Mazzotti, H. Tai, K. M. Shakesheff and S. M. Howdle, J. Polym. Sci., Part B: Polym. Phys., 2007, 46, 483-496.
10 S. Beuermann, M. Buback, M. Gadermann, M. Jürgens and D. P. Saggu, J. Supercrit. Fluids, 2006, 39, 246-252.

11 S. Beuermann, M. Buback and M. Jürgens, Ind. Eng. Chem. Res., 2003, 42, 6338-6342.

12 J. L. Kendall, D. A. Canelas, J. L. Young and J. M. DeSimone, Chem. Rev., 1999, 99, 543-563.

13 H. Tai, W. Wang, R. Martin, J. Liu, E. Lester, P. Licence, H. W. Woods and S. M. Howdle, Macromolecules, 2005, 38, 355-363.

14 E. Möller and S. Beuermann, Macromol. React. Eng., 2011, 5, 8-21.

15 A. Galia, G. Caputo, G. Spadaro and G. Filardo, Ind. Eng. Chem. Res., 2002, 41, 5934-5940.

16 I. Idriss, A. Yu, S. M. Howdle, A. K. Whittaker and K. J. Thurecht, Green Chem., 2011, 13, 2032-2037.

17 F. Stassin, O. Halleux and R. J. Jérôme, Macromolecules, 2001, 34, 775-781.

18 F. Stassin and R. Jérôme, Chem. Commun., 2003, 232-233.

19 D. Bratton, M. Brown and S. M. Howdle, Macromolecules, 2005, 38, 1190-1195.

20 D. D. Hille and M. V. Pishko, Macromol. Rapid Commun., 1999, 20, 511-514.

21 R. Mazarro, A. de Lucas, I. García and J. F. Rodríguez, J. Biomed. Mater. Res., Part B, 2008, 85, 196.

22 D. Bratton, M. Brown and S. M. Howdle, Chem. Commun., 2004, 808-809.

23 M. Türk, J. Supercrit. Fluids, 2009, 47, 537-545.

24 E. Reverchon, R. Adami, S. Cardea and G. Della Porta, J. Supercrit. Fluids, 2009, 47, 484-492.

25 M. Buback and C. Hinton, in High-pressure techniques in chemistry and physics: a practical approach, ed. N. Isaacs and W. Holzapfel, Oxford Univ. Press, 1997.

26 M. Tarnacka, T. Flak, M. Dulski, S. Pawlus, K. Adrjanowicz, A. Swinarew, K. Kaminski and M. Paluch, Polymer, 2014, 55, 1984-1990.

27 H. R. Kricheldorf, I. Kreiser-Saunders and A. Stricker, Macromolecules, 2000, 33, 702-709.

28 W. Leitner, Acc. Chem. Res., 2002, 35, 746-756.

29 E. Möller and S. Beuermann, Macromol. React. Eng., 2011, 5, 8-21.

30 C. Kirby and M. A. McHugh, Chem. Rev., 1999, 99, 565-602.

31 C. N. McEwan, C. Jackson and B. S. Larsen, Int. J. Mass Spectrom. Ion Proc., 1996, 160, 387-394.

32 C. Jackson, B. Larson and C. N. McEwen, Anal. Chem., 1996, 68, 1303-1308.

33 G. Kortaberria, A. Jimeno, P. Arruti, K. de la Caba, P. Remiro, A. Eceiza and I. Mondragon, Macromol. Symp., 2006, 239, 152-158.

34 M. Soccio, N. Lotti, L. Finelli, M. Gazzano and A. Munari, J. Polym. Sci., Part B: Polym. Phys., 2010, 48, 1901-1910.

35 I. Engelberg and J. Kohn, Biomaterials, 1991, 12, 292-304.

36 P. A. Gunatillake and R. Adhikari, Eur. Cells Mater., 2003, 5, 1-16. 